\title{
Aplicação da NBR 15505-2:2019 na Análise dos Trechos da Trilha do Rio do Boi, no Parque Nacional de Aparados da Serra, Sul do Brasil
}

\author{
Laís Helena Mazzali ${ }^{1}$, Lucas Ribeiro Diaz ${ }^{2}$, Masato Kobiyama ${ }^{1} \&$ Karla Campagnolo $^{1}$
}

Recebido em 07/07/2020 - Aceito em 26/02/2021

1 Universidade Federal do Rio Grande do Sul, Instituto de Pesquisas Hidráulicas, Grupo de Pesquisas de Desastres Naturais, (UFRGS/PH/GPDEN),
Porto Alegre/RS, Brasil. CEP: 91.501-970. <lais.gae@gmail.com, masato.kobiyama@ufrgs.br, kbcampagnolo@gmail.com>.
2 Universidade Federal do Rio Grande do Sul, Centro Estadual de Pesquisas em Sensoriamento Remoto e Meteorologia, Programa de Pós-
Graduação em Sensoriamento Remoto, (UFRGS/CEPSRM/PPGSR), Porto Alegre/RS, Brasil. CEP: 91.501-970. <l.ribeiro.diaz@vu.nl>.

RESUMO - A trilha do Rio do Boi, localizada no Parque Nacional de Aparados da Serra, é popularmente conhecida como uma trilha de alto grau de dificuldade. Contudo, não existem estudos com uma classificação padronizada ou normativa referente a esse tipo de análise. Portanto, o objetivo do trabalho foi classificar o percurso da trilha do Rio do Boi de acordo com a Norma Brasileira 155052:2019. Para desenvolver esta classificação, a trilha foi percorrida para mapeamento e dividida em 27 trechos, os quais foram classificados com valores/classes de 1 a 5 para quatro critérios (severidade do meio, orientação no percurso, condições do terreno e grau de esforço físico). Os resultados obtidos mostram que a trilha do Rio do Boi é classificada como: bastante severa (classe 4); exigindo a identificação de acidentes geográficos e de pontos cardeais (classe 3); o percurso é composto por trilhas escalonadas ou terrenos irregulares (classe 3); e o esforço é significativo (classe 3). A presente classificação possui caráter preliminar, contudo, pode contribuir tanto para suprir a carência de materiais que classifiquem a trilha de acordo com critérios normatizados quanto para a realização de atividades turísticas mais seguras na região.

Palavras-chave: Educação ambiental; ecoturismo; perigo.

\section{Application of NBR 15505-2:2019 for the Analysis of the Stretches of the Boi River Trail, in the Aparados da Serra National Park, Southern Brazil}

\begin{abstract}
The Boi River trail, located in Aparados da Serra National Park, is popularly known as a trail of high difficulty degree. However, there are no studies with a standardized or normative classification referring to this kind of analysis. Therefore, the objective of the present study was to classify the course of the Boi River trail with the Brazilian Normative 15505-2:2019. To develop this classification, the Trail was carried out in order to map it, the trail was divided it into 27 stretches, which were classified with values/classes from 1 to 5 based on four criteria (environment severity, course orientation, land conditions, and degree of physical effort). The obtained results show that the Boi River trail is classified as: quite severe (Class 4); requiring the identification of geographical accidents and cardinal points (Class 3 ); the course is composed by stepped trails or irregular terrain (Class 3); and the effort is significant (Class 3). The classification can be preliminary, however, it can contribute both to supply the shortage of materials that classify the trail according to standardized criteria and to carry out safer tourist activities in the region.
\end{abstract}

Keywords: Environmental education; ecotourism; hazard.

\section{Aplicación de la NBR 15505-2:2019 en el Análisis de los Tramos del Sendero Rio do Boi, en el Parque Nacional Aparados da Serra, Sur de Brasil}

RESUMEN - El sendero Rio do Boi, ubicado en el Parque Nacional Aparados da Serra, es conocido popularmente como un sendero con un alto grado de dificultad. Sin embargo, no existen estudios con una clasificación estandarizada o normativa que haga referencia a este tipo de análisis. Por tanto, el objetivo del presente trabajo fue clasificar el trayecto del Sendero Rio do Boi de acuerdo con el 
Estándar Brasileño 15505-2:2019. Para desarrollar dicha clasificación, el sendero fue recorrido para mapeo y divido en 27 tramos, que fueron clasificados con valores/clases del 1 al 5 para cuatro criterios (severidad del entorno, orientación en el trayecto, condiciones del terreno y grado del esfuerzo físico). Los resultados obtenidos muestran que el Sendero Rio do Boi está clasificado como: bastante severo (Clase 4); requiriendo la identificación de accidentes geográficos y puntos cardinales (Clase 3); el trayecto consta de senderos escalonados o terreno irregular (Clase 3); y el esfuerzo es significativo (Clase 3). La clasificación actual tiene un carácter preliminar, sin embargo puede contribuir tanto a proveer la falta de materiales que clasifican el sendero de acuerdo con criterios estandarizados como para la realización de actividades turísticas más seguras en la región.

Palabras clave: Educación ambiental; ecoturismo; amenaza.

\section{Introdução}

Após a Segunda Guerra Mundial, e especialmente no século XXI, a qualidade de vida da população mundial vem melhorando cada vez mais, apesar do nível de estresse do indivíduo também ter aumentado. Como consequência e como forma de alívio ao estresse, as pessoas têm recorrido ao turismo. Entretanto, esta intensificação do turismo, se realizada de forma descontrolada, pode causar prejuízos ao ambiente local. Isso fez com que a sociedade pensasse no desenvolvimento de um turismo sustentável.

Juntamente com a consciência ambiental, principalmente a partir da RIO92 (Conferência das Nações Unidas sobre o Meio Ambiente e o Desenvolvimento), o ecoturismo vem ganhando seu espaço dentro do cenário nacional brasileiro. Segundo Brasil (2008), ecoturismo é um segmento da atividade turística que utiliza, de forma sustentável, o patrimônio natural e cultural, incentivando sua conservação e buscando a formação de uma consciência ambientalista por meio da interpretação do ambiente, promovendo assim o bem-estar das populações.

Sabendo que atualmente os turistas buscam experiências alternativas de maior conexão com a natureza, diversos setores possuem suas próprias definições do ecoturismo e turismo de aventura. Isso gera até uma confusão da interpretação do ecoturismo (Donohoe \& Needham, 2006). O ecoturismo pode ser feito utilizando carros, barcos ou caminhadas a pé, mas certamente o turismo de aventura mais praticado são as caminhadas. Segundo Brasil (2008), percursos para fins de contemplação são a melhor maneira de interpretação da natureza, fazendo o turista sentila efetivamente. Blengini et al. (2019) afirmam que essa busca por uma maior conectividade com a natureza fez aumentar a importância da implementação de trilhas interpretativas.
Nesse sentido, ainda existem muitos locais no Brasil em que o ecoturismo precisa ser melhor aproveitado (Aguiar et al., 2010). Sabe-se que os locais mais apropriados para o ecoturismo são os Parques Nacionais. Segundo Canto-Silva \& Silva (2017), o objetivo dos parques é de preservar os ecossistemas naturais de grande relevância ecológica e beleza cênica, possibilitando a realização de pesquisas científicas, o desenvolvimento de atividades de educação $e$ interpretação ambiental, a recreação em contato com a natureza e o turismo ecológico.

Portanto, o estabelecimento e o planejamento de trilhas interpretativas adequadas nos parques e em unidades de conservação é a melhor forma da interação entre o homem e a natureza, tendo em vista que elas não são somente um caminho em meio à natureza, mas também permitem a obtenção de diversas informações da mesma (Blengini et al., 2019).

Existem diversas metodologias sendo aplicadas e usadas para avaliar as trilhas interpretativas no Brasil. Andrade \& Rocha (2008) apresentaram um manual de metodologia de classificação de trilhas em decorrência da sua função, forma e sua dificuldade, e também da implantação prática das trilhas. Ao final, os autores sugerem que a classificação das trilhas deve ser feita de acordo com: declividade, distância, vegetação e presença de animais. Assim, aplicando esse manual para caracterizar uma trilha no parque estadual da Serra Furada/SC, Aguiar et al. (2010) propuseram a realização de um planejamento socioambiental, demonstrando a importância deste planejamento, a fim de obter maior sustentabilidade do parque. Garcia et al. (2011) relataram a construção de várias trilhas interpretativas na estação ecológica de Angatuba/ SP, com planejamento e avaliação adequada com base de manual de Andrade \& Rocha (2008). 
Alguns estudos de avaliação são a partir do diagnóstico ambiental que utiliza o método de Indicadores de Avaliação de Pontos Interpretativos (IAPI), que considera, entre outros fatores, declividade, rocha, solo e vegetação. Esta metodologia foi utilizada por Ferreira (2015), nas trilhas da Pedra Selada e da Pedra Boca do Sapo no parque estadual de Pedra Selada/RJ, propondo ao final do estudo ações de manejo para o desenvolvimento destas trilhas. No caso de Silva et al. (2016), que mapearam uma trilha no parque nacional do Itatiaia/RJ, o grau de dificuldade foi classificado com base na declividade, uso do solo e presença de água.

Apresentando exemplos baseados no setor de turismo da Nova Zelândia, Espiner et al. (2017) conceitualmente discutiram as ideias que um tratamento crítico do nexo sustentabilidaderesiliência pode oferecer, tanto a acadêmicos quanto a profissionais do turismo. Como o ecoturismo está sendo realizado em um ecossistema que sofre frequentemente com perigos naturais, a introdução da resiliência deve ser fundamental na gestão de desastres naturais no ecoturismo.

$\mathrm{E}$ mais recentemente, Ferrarese et al. (2019) realizaram entrevistas com turistas da trilha interpretativa localizada no parque municipal dos Morros, em Santa Maria/RS, e suas respostas demonstraram que essa trilha contribui à construção da percepção e da interpretação ambiental. Blengini et al. (2019) propuseram adequações em uma trilha situada na Reserva Particular do Patrimônio Natural (RPPN) do Caju, em Itaporanga d'Ajuda/SE, a partir, das respostas dos turistas aos questionamentos da sua pesquisa. Também por meio de entrevistas, sabendo que as atividades em trilhas podem expor os usuários a riscos, Neves \& Costa (2019) analisaram os riscos ambientais e os riscos à segurança dos visitantes na trilha do Pico da Tijuca, no parque nacional da Tijuca/RJ.

Outra forma de metodologia de avaliação é através da Norma Brasileira (NBR) 15505-2 "Turismo de aventura - Caminhada - Parte 2: Classificação de percursos" (ABNT, 2019), publicada inicialmente em 2008 e atualizada em 2019. Apesar de ser uma norma padronizada, ainda poucos trabalhos técnico-científicos a utilizaram. Por exemplo, Costa (2012), Melo \& Aguiar (2016), e Magri et al. (2018) discutiram as trilhas com essa NBR para trabalhos nos municípios de Brotas/
SP, Taquaruçu/TO e Parque Nacional da Serra da Canastra/MG, respectivamente. Todos esses estudos focaram na severidade, na dificuldade $e$ nos riscos para os turistas.

Para a trilha do Rio do Boi, não existe uma padronização ou normativa referente ao seu grau de dificuldade. Ademais, no que diz respeito às informações técnicas e científicas, a existência de material é ainda mais escassa, sendo que as fontes de informações sobre a classificação da trilha quanto à sua dificuldade são apenas de sites de empresas de turismo e dos próprios guias locais.

Neste contexto, o objetivo do presente trabalho foi analisar a trilha do Rio do Boi, localizada no parque nacional de Aparados da Serra (PNAS), com base na NBR 15505-2:2019. Embora a NBR já tenha sido utilizada para analisar o perigo de algumas trilhas para turistas no Brasil, nenhum trabalho considerou as características meteorológicas. Uma vez que os graus de dificuldade e de perigos na trilha do Rio do Boi são fortemente influenciados pelos eventos extremos, que causam inundações bruscas (enxurradas), escorregamentos, fluxo de detritos, entre outros. E como esses perigos resultam das condições hidrológicas, geomorfológicas e geológicas, tal classificação necessita do conhecimento $e$ aplicação dessas ciências.

Hardiman \& Burgin (2010) afirmam que o turismo $e$ a recreação em cânions estão crescendo em popularidade em vários países, $e$ isso se reflete até na formação de associações nacionais de turismo e recreação de aventura. Relatando as características geológicas da região do PNAS, Godoy et al. (2012) apresentaram diversos geossítios educativos, com altos potenciais turísticos. Se tais geossítios forem popularizados, aumentará ainda mais a procura turística pelo cânion Itaimbezinho.

\section{Materiais e métodos \\ Área de estudo}

A área de estudo é a trilha do Rio do Boi, localizada no Parque Nacional de Aparados da Serra (PNAS) na divisa entre dois municípios: Cambará do Sul/RS e Praia Grande/SC (Figura 1). Entretanto, a trilha está totalmente inserida no município de Praia Grande. 


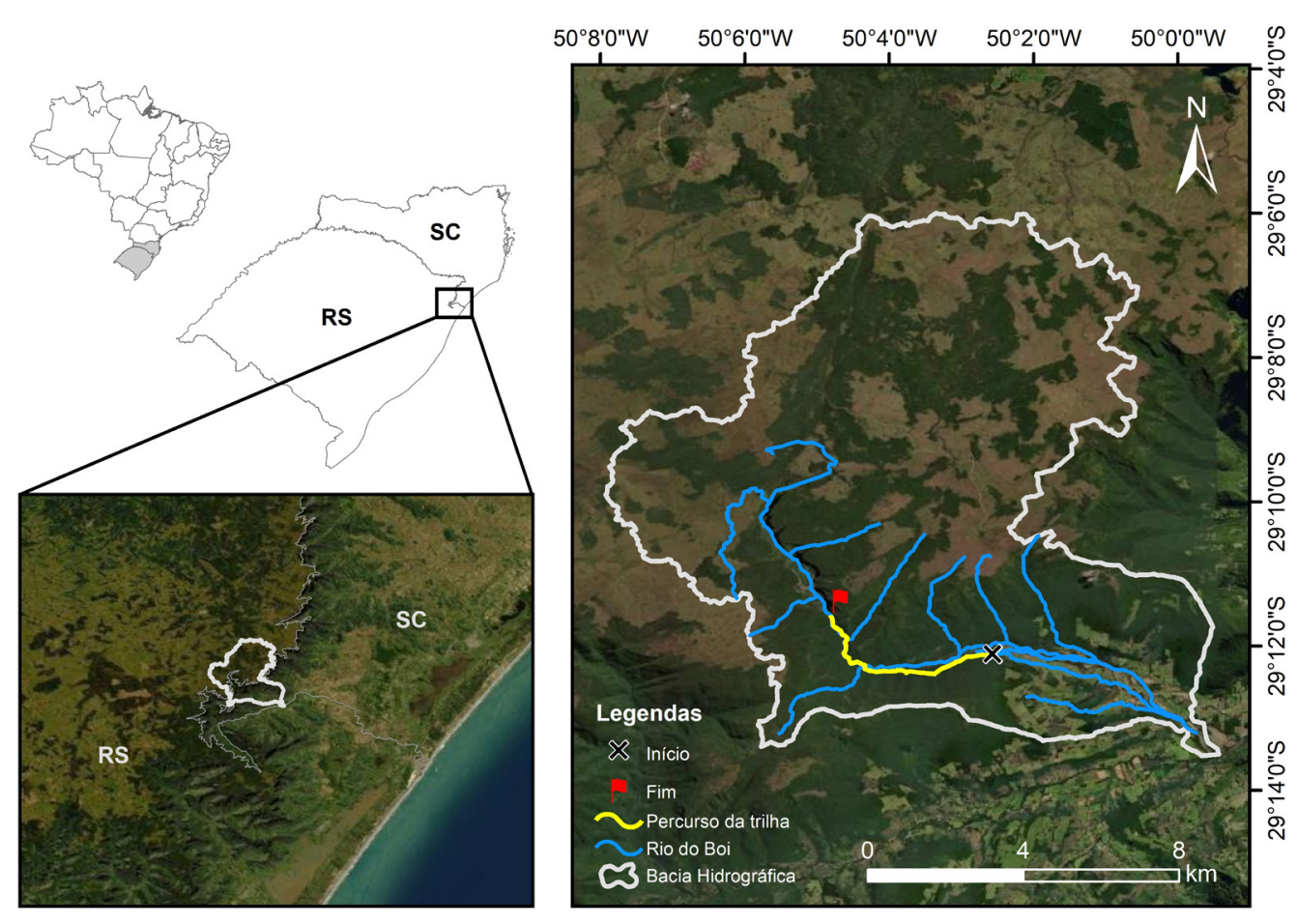

Figura 1 - Localização da trilha e da bacia hidrográfica do Rio do Boi.

A trilha é localizada no interior da fenda do cânion do Itaimbezinho, junto ao leito do rio $e$ ao lado de paredões de até $720 \mathrm{~m}$ de altura. Seu percurso total é cerca de $12 \mathrm{~km}$ de extensão (ida e volta), a partir do posto de informação $e$ controle do Rio do Boi do Instituto Chico Mendes de Conservação da Biodiversidade. Os turistas costumam levar entre 6 e 8 horas para completar o trajeto. Boa parte deste fica em um terreno irregular, sobre pedras escorregadias no leito do rio, contando com em torno de 20 travessias completas do mesmo. Diante disso, a Trilha do Rio do Boi é conhecida como uma trilha desafiadora. Soma-se a isso o fato de que, por ser realizada dentro da fenda do cânion, o resgate - em uma possível situação de emergência - não se trata de uma operação simples.

\section{Levantamento em campo}

A caminhada na trilha do Rio do Boi foi realizada ao longo do dia 26 de outubro de 2018. Durante o percurso, utilizou-se um GPS portátil e uma câmera fotográfica para registro da localização e imagens, respectivamente. $\mathrm{O}$ trajeto de ida foi realizado em aproximadamente 4 horas, incluindo paradas para descanso e contemplação.
Já o caminho da volta foi completado em apenas 2 horas com poucas interrupções, devido à ocorrência de uma intensa chuva. Considerando ida e volta, o percurso da trilha teve cerca de $12 \mathrm{~km}$, e não ocorreram a omissão de trechos.

\section{Avaliação e classificação do percurso na Trilha}

A classificação do percurso foi realizada com base na NBR 15.505-2 (ABNT, 2019). O procedimento consiste na divisão do percurso em trechos, que foram avaliados separadamente conforme 4 critérios: severidade do meio, orientação no percurso, condições do terreno e grau de esforço físico. Salienta-se que essa avaliação pode variar a partir da estação do ano.

A cada parâmetro é atribuído um valor de 1 a 5 , sendo definido para o percurso o valor do trecho com maior valor. No caso dos critérios de severidade do meio e condições do terreno, quando um percurso tiver $80 \%$ ou mais de sua extensão classificado com valor menor do que o valor atribuído ao percurso total da trilha, deve ser dada tal informação. Por exemplo, em um percurso de $10 \mathrm{~km}$ avaliado como nível 3 para severidade do meio, dos quais $8 \mathrm{~km}$ são classificados como 
nível 1 (80\%), este seria informado como sendo de nível 3, mas com 8km do percurso de nível 1 (ABNT, 2019).

A severidade do meio refere-se a perigos $e$ outras dificuldades decorrentes do meio natural, como temperatura, pluviosidade, riscos de quedas ou facilidade de resgate, que podem ocorrer ao longo do percurso (ABNT, 2019). A análise foi feita com base na ocorrência de 20 fatores, ponderados para cada um dos trechos determinados. São exemplos desses fatores: exposição a desprendimentos espontâneos de pedras durante o percurso $e$ a alta probabilidade de chuvas intensas ou contínuas para o período. A descrição completa e detalhada dos 20 fatores encontra-se em ABNT (2019). Estes itens foram analisados durante o percurso da trilha.

Além disso, os fatores foram relacionados com os dados da estação meteorológica situada na sede doPNAS (DatumSIRGAS2000:-29.158387 $-50.079778^{\circ}$ ), instalada pelo Grupo de Pesquisa em Desastres Naturais (GPDEN) da UFRGS. Para tal foram utilizados dados da estação do período de janeiro a dezembro de 2018. Por fim, se dá o somatório do número de fatores que ocorrem para cada um dos trechos.

Os valores de temperaturas mínimas $e$ máximas do mês foram obtidas através da média das menores e maiores temperaturas diárias registradas, respectivamente. $\mathrm{O}$ mesmo foi feito para velocidade máxima do vento (média das máximas diárias obtidas pela estação).

A orientação no percurso depende do grau de dificuldade para orientação, como presença de sinalização, trilhas bem demarcadas ou existência de pontos de referência para completar o percurso (ABNT, 2019). Dessa forma, a avaliação do percurso foi feita pela avaliação da facilidade de orientação ao percorrer cada um dos trechos.

O terceiro critério são as condições do terreno, que correspondem aos aspectos encontrados no percurso em relação ao piso e às condições para percorrê-lo, como tipos de pisos, trechos com obstáculos, trechos com pedras soltas, entre outros.

Por último, o critério de grau de esforço físico se refere à quantidade de esforço físico requerido para cumprir o percurso, levando em conta a extensão e os desníveis (subidas $e$ descidas), considerando um praticante comum.
ABNT (2019) considera que o índice de esforço para caminhada em percursos de turismo deve ser calculado considerando-se uma pessoa adulta, não-esportista e carregando bagagem leve.

Aqui salienta-se que o resultado do tempo de percurso não traduz necessariamente o tempo cronológico da caminhada, pois o tempo real pode variar em função do condicionamento físico do caminhante, condições do tempo, ritmo de marcha, velocidade média, e número de paradas. Assim, em relação à estimativa de esforço necessário, o critério considera a distância dos trechos e a influência dos desníveis de subidas e descidas. O tempo de deslocamento em superfícies planas é:

$$
T_{h}=\frac{D_{p}}{V_{h}}
$$

em que $T_{h}$ é o tempo de deslocamento na horizontal [h]; $D_{p}$ é a distância percorrida no trecho $[\mathrm{km}]$; e $V_{h}$ é a velocidade média na horizontal $[\mathrm{km} / \mathrm{h}]$.

A distância percorrida no trecho foi calculada por meio de uma ferramenta de Sistema de Informações Geográficas (SIG). A velocidade a ser considerada está associada às características do piso do trecho em questão. No caso de piso fácil (por exemplo, estradas e pistas), piso moderado (trilhas, caminhos lisos e prados) e piso difícil (caminhos pedregosos e leitos de rios), os valores da velocidade são considerados $4 \mathrm{~km} / \mathrm{h}$, $3 \mathrm{~km} / \mathrm{h}$, e $2 \mathrm{~km} / \mathrm{h}$, respectivamente (ABNT, 2019). Por sua vez, a fórmula para calcular o tempo em superfícies com desnível é:

$$
T=\frac{D}{V}
$$

em que $T$ é o tempo de deslocamento na subida ou descida [h]; $D$ é o desnível [m]; e Vé a velocidade de deslocamento vertical em aclive ou declive $[\mathrm{m} / \mathrm{h}]$.

Os desníveis foram determinados com GPS durante o percurso da trilha. ABNT (2019) sugere as velocidades de 200 e $300 \mathrm{~m} / \mathrm{h}$ para aclive e declive, respectivamente. $\mathrm{O}$ índice de esforço é o somatório dos tempos dos trechos na horizontal e na vertical, ou seja:

$$
I E_{\mathrm{ABNT}}=\text { MaiorT }+\frac{\text { MenorT }}{2}
$$

em que $I E_{\mathrm{ABNT}}$ é o índice de esforço para caminhada em percursos de turismo [h]; MaiorT é o maior somatório dos tempos de deslocamento [h]; e MenorT é o menor somatório dos tempos de deslocamento [h]. 
Por fim, o percurso foi classificado quanto aos critérios mencionados (Tabela 1). O esquema de cores utilizado na tabela ilustra o que foi utilizado na Figura 5.

Tabela 1 - Classificação de percursos segundo a severidade, orientação, condições do terreno e índice de esforço físico, adaptada da NBR 15.505-2:2019.

\begin{tabular}{|c|c|c|c|c|c|}
\hline Critério & 1 & 2 & 3 & 4 & 5 \\
\hline $\begin{array}{l}\text { Severidade } \\
\text { do meio }\end{array}$ & $\begin{array}{l}\text { Pouco severo (até } 3 \\
\text { fatores) }\end{array}$ & $\begin{array}{l}\text { Moderadamente } \\
\text { severo ( } 4 \text { ou } 5 \text { fatores) }\end{array}$ & Severo (6 a 8 fatores) & $\begin{array}{l}\text { Bastante severo ( } 9 \text { a } \\
12 \text { fatores) }\end{array}$ & $\begin{array}{l}\text { Muito severo (pelo } \\
\text { menos } 13 \text { fatores) }\end{array}$ \\
\hline $\begin{array}{l}\text { Orientação } \\
\text { do percurso }\end{array}$ & $\begin{array}{l}\text { Caminhos e } \\
\text { cruzamentos bem } \\
\text { definidos: Caminhos } \\
\text { principais bem } \\
\text { delimitados ou } \\
\text { sinalizados, com } \\
\text { cruzamentos claros } \\
\text { com indicação } \\
\text { explícita ou implícita. } \\
\text { Manter-se sobre } \\
\text { o caminho não } \\
\text { exige esforço } \\
\text { de identificação } \\
\text { do traçado. } \\
\text { Eventualmente, } \\
\text { pode ser necessário } \\
\text { acompanhar uma } \\
\text { linha marcada por um } \\
\text { acidente geográfico } \\
\text { inconfundível (e.g., } \\
\text { praia ou margem de } \\
\text { lago). }\end{array}$ & $\begin{array}{l}\text { Caminho ou } \\
\text { sinalização que indica } \\
\text { a continuidade: Existe } \\
\text { um traçado claro } \\
\text { do caminho sobre o } \\
\text { terreno ou sinalização } \\
\text { para a continuidade } \\
\text { do percurso. Requer } \\
\text { atenção para a } \\
\text { continuidade e } \\
\text { o cruzamento de } \\
\text { outros traçados, mas } \\
\text { sem necessidade de } \\
\text { uma interpretação } \\
\text { precisa dos acidentes } \\
\text { geográficos. }\end{array}$ & $\begin{array}{l}\text { Requer a identificação } \\
\text { de acidentes } \\
\text { geográficos e de } \\
\text { pontos cardeais: } \\
\text { Ainda que o itinerário } \\
\text { se desenvolva por } \\
\text { traçado sobre trilhas, } \\
\text { percursos marcados } \\
\text { por acidentes } \\
\text { geográficos** ou } \\
\text { marcas de passagem } \\
\text { de outras pessoas, } \\
\text { a escolha do } \\
\text { itinerário depende do } \\
\text { reconhecimento dos } \\
\text { acidentes geográficos } \\
\text { e dos pontos cardeais. }\end{array}$ & $\begin{array}{l}\text { Exige habilidades } \\
\text { de navegação } \\
\text { fora do traçado: } \\
\text { Não existe traçado } \\
\text { sobre o terreno, } \\
\text { nem segurança de } \\
\text { contar com pontos } \\
\text { de referência } \\
\text { no horizonte. O } \\
\text { itinerário depende } \\
\text { da compreensão do } \\
\text { terreno e do traçado } \\
\text { de rumos. }\end{array}$ & $\begin{array}{l}\text { Requer navegação } \\
\text { para utilizar trajetos } \\
\text { alternativos e } \\
\text { não conhecidos } \\
\text { previamente: O } \\
\text { itinerário depende } \\
\text { da compreensão do } \\
\text { terreno e do traçado } \\
\text { de rotas, além de } \\
\text { exigir capacidade } \\
\text { de navegação para } \\
\text { completar o percurso. } \\
\text { O itinerário pode } \\
\text { ser interrompido } \\
\text { inesperadamente } \\
\text { por obstáculos } \\
\text { que necessitem ser } \\
\text { contornados. }\end{array}$ \\
\hline $\begin{array}{l}\text { Condições } \\
\text { do terreno }\end{array}$ & $\begin{array}{l}\text { Percurso em } \\
\text { superfícies planas: } \\
\text { Estradas e pistas } \\
\text { para veículos, } \\
\text { independentemente } \\
\text { da sua inclinação. } \\
\text { Caminhos com } \\
\text { degraus com piso } \\
\text { plano e regular. } \\
\text { Praias (de areia ou de } \\
\text { cascalho) com piso } \\
\text { nivelado e firme. }\end{array}$ & $\begin{array}{l}\text { Percurso por caminhos } \\
\text { sem obstáculos: } \\
\text { Terrenos firmes, mas } \\
\text { que mantenham } \\
\text { a regularidade do } \\
\text { piso, trilhas bem } \\
\text { marcadas (sem } \\
\text { grandes inclinações } \\
\text { ou obstáculos que } \\
\text { requeiram grande } \\
\text { esforço físico), } \\
\text { terrenos uniformes } \\
\text { pouco inclinados. }\end{array}$ & $\begin{array}{l}\text { Percurso por trilhas } \\
\text { escalonadas ou } \\
\text { terrenos irregulares: } \\
\text { Percurso com } \\
\text { obstáculos ou } \\
\text { degraus irregulares } \\
\text { (tamanho, altura e } \\
\text { inclinação desiguais), } \\
\text { terrenos irregulares, } \\
\text { pedregosos, de pedras } \\
\text { soltas ou instáveis, } \\
\text { raízes expostas, } \\
\text { areões, grandes } \\
\text { erosões. }\end{array}$ & $\begin{array}{l}\text { Percurso com } \\
\text { obstáculos: Caminhos } \\
\text { com obstáculos que } \\
\text { podem exigir saltos ou } \\
\text { a utilização das mãos } \\
\text { até I Sup. (graduação } \\
\text { UIAA para escalada } \\
\text { ou progressão } \\
\text { vertical). }\end{array}$ & $\begin{array}{l}\text { Percurso que requer } \\
\text { técnicas verticais: } \\
\text { Trechos que exigem } \\
\text { técnicas de escalada } \\
\text { do grau II até III Sup. } \\
\text { (graduação UIAA } \\
\text { para escalada ou } \\
\text { progressão vertical). } \\
\text { Exige a utilização } \\
\text { de equipamentos e } \\
\text { técnicas específicas. }\end{array}$ \\
\hline $\begin{array}{l}\text { Grau de } \\
\text { esforço } \\
\text { físico }\end{array}$ & $\begin{array}{l}\text { Pouco esforço (até } \\
\left.1 h^{*}\right)\end{array}$ & $\begin{array}{l}\text { Esforço moderado } \\
\text { (mais de } 1 \text { e até } 3 \mathrm{~h} \text { ) }\end{array}$ & $\begin{array}{l}\text { Esforço significativo } \\
\text { (mais de } 3 \text { e até } \\
6 h^{* *} \text { ) }\end{array}$ & $\begin{array}{l}\text { Esforço intenso (mais } \\
\text { de } 6 \text { e até } 10 \mathrm{~h} \text { ) }\end{array}$ & $\begin{array}{l}\text { Esforço extraordinário } \\
\text { (mais de 10h) }\end{array}$ \\
\hline
\end{tabular}

Obs.:

* Estimativa de duração da atividade de caminhada [h]: A medida do tempo é expressa pelo índice de esforço para caminhada em percursos de turismo e não traduz necessariamente o tempo cronológico de duração de uma atividade.

**Rios, fundos de vales, costas, cristas, costões de pedras, entre outros.

\section{Resultados e Discussão}

\section{Segmentação da trilha com trechos}

A partir da realização da trilha, esta foi dividida em 27 trechos, considerando que o trajeto de ida é semelhante ao da volta. Na segmentação (Figura 2), consideraram-se como "pontos de separação" (grifados em vermelho) na entrada na trilha de escape, na divisão na trilha, nas subidas $e$ descidas acentuadas, nas travessias do rio $e$ nos pontos de maior perigo, devido a quedas de blocos dos paredões do cânion. Cada um dos trechos foi analisado segundo os quatro critérios apresentados na anteriormente (Tabela 1). 


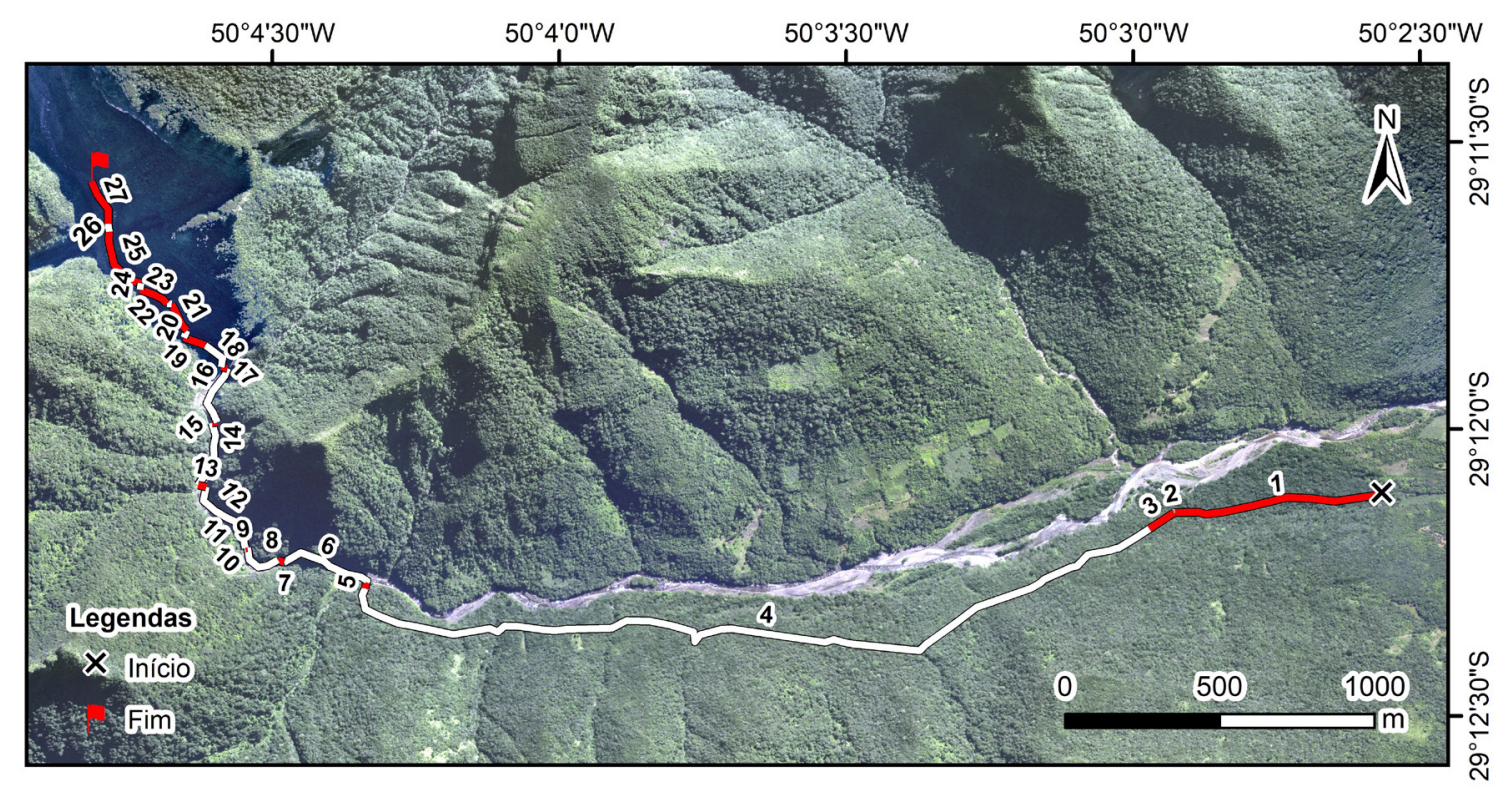

Figura 2 - Segmentação da Trilha do Rio do Boi, onde os números indicam os trechos.

Contabilizou-se, para cada um dos trechos, o número de ocorrência dos 20 fatores listados na NBR 15.505-2:2019 para o critério de severidade do meio.

\section{Análise Meteorológica}

A partir dos dados anuais obtidos na estação meteorológica situada junto à sede do PNAS (Figura 3), e considerando os efeitos orográficos predominantes na área de estudo, fez-se o enquadramento dos trechos. Para nenhum deles registrou-se a ocorrência dos seguintes itens: "alta probabilidade de que pela noite a temperatura caia abaixo de $0^{\circ} \mathrm{C}$ " (Figura 3C), "alta probabilidade de que a umidade relativa seja inferior aos 30\%" (Figura 3E) e "alta probabilidade de exposição ao calor em temperatura acima de $32^{\circ} \mathrm{C}$ " (Figura 3D).

Os fatores "alta probabilidade de chuvas intensas ou contínuas para o período" (Figura 3A) $e$ "alta probabilidade de que a temperatura caia abaixo de $5^{\circ} \mathrm{C}$ e a umidade relativa do ar supere 90\%" (Figuras 3C e 3E) foram enquadrados em todos os trechos.

Pode-se observar que outubro (quando a trilha foi percorrida) foi o terceiro mês mais chuvoso em 2018 (Figura 3A). Isso demonstra que a classificação do percurso não foi realizada em um período de condições meteorológicas totalmente favoráveis, o que poderia mascarar os resultados. Como a ocorrência de deslizamentos encontra-se após elevadas precipitações, Nonnemacher et al. (2019) sugerem que uma medida de prevenção a este tipo de desastres na trilha do Rio do Boi é a sua interdição em caso de chuvas intensas, evidenciando a importância do monitoramento meteorológico. Costa (2012) recomenda que um guia de caminhadas deva ter, entre suas aptidões, conhecimentos básicos de meteorologia.

Com relação à velocidade do vento (Figura 3G) demonstrou que as médias máximas ficaram em torno de 2,78m/s. Entretanto, Leite \& Virgens Filho (2006) alertam que esta se trata de uma variável aleatória, com variabilidade sazonal, mensal, diária e até horária nos valores médios.

Além disso, dois itens foram aferidos para quase $90 \%$ do percurso, tanto em número de trechos quanto em distância. São eles: (i) "tempo de realização da atividade igual ou superior a $1 \mathrm{~h}$ de marcha sem passar por um lugar habitado, um telefone de socorro (ou sinal de celular ou radiocomunicador) ou uma estrada aberta com fluxo de veículos"; e (ii) "tempo de realização da atividade igual ou superior a $3 \mathrm{~h}$ de marcha sem passar por um lugar habitado, um telefone de socorro (ou sinal de celular ou radiocomunicador) ou uma estrada aberta com fluxo de veículos".

Cabe salientar que nessa análise levou-se também em consideração que as águas do rio $e$ das nascentes, ao longo da trilha de escape, são potáveis. 

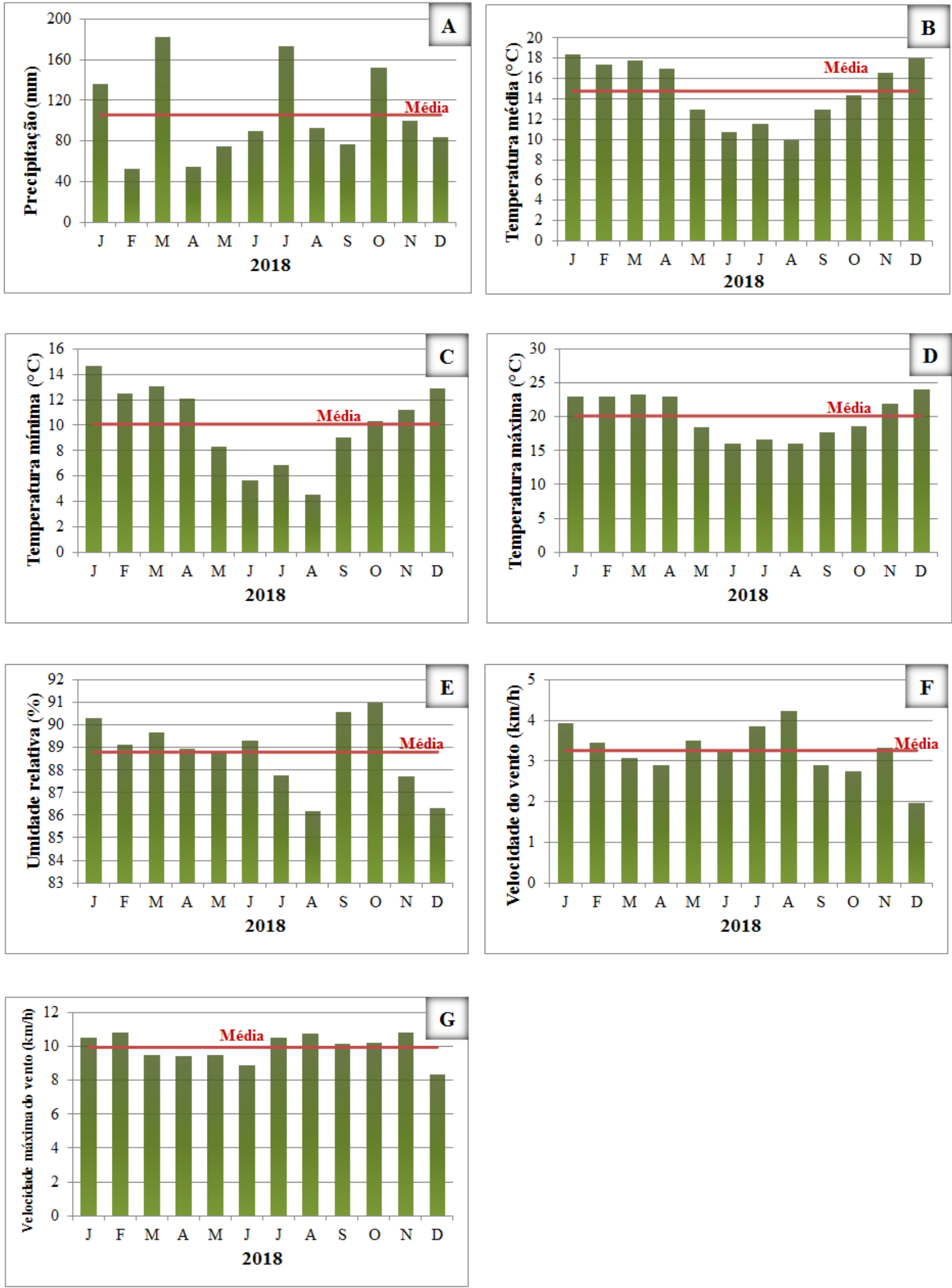

Figura 3 - Caracterização anual do tempo obtida na estação meteorológica localizada na sede do PNAS: A) precipitação; B) temperatura média; C) temperatura mínima; D) temperatura máxima; E) umidade relativa; F) velocidade média do vento; e G) velocidade máxima do vento. 


\section{Análise do percurso da trilha}

As Figuras $4 \mathrm{~A}$ e $4 \mathrm{~B}$ apresentam o piso pedregoso do Rio do Boi e o perigo de queda de blocos, respectivamente, que podem dificultar a locomoção ou até mesmo representar o perigo aos turistas durante o percurso.

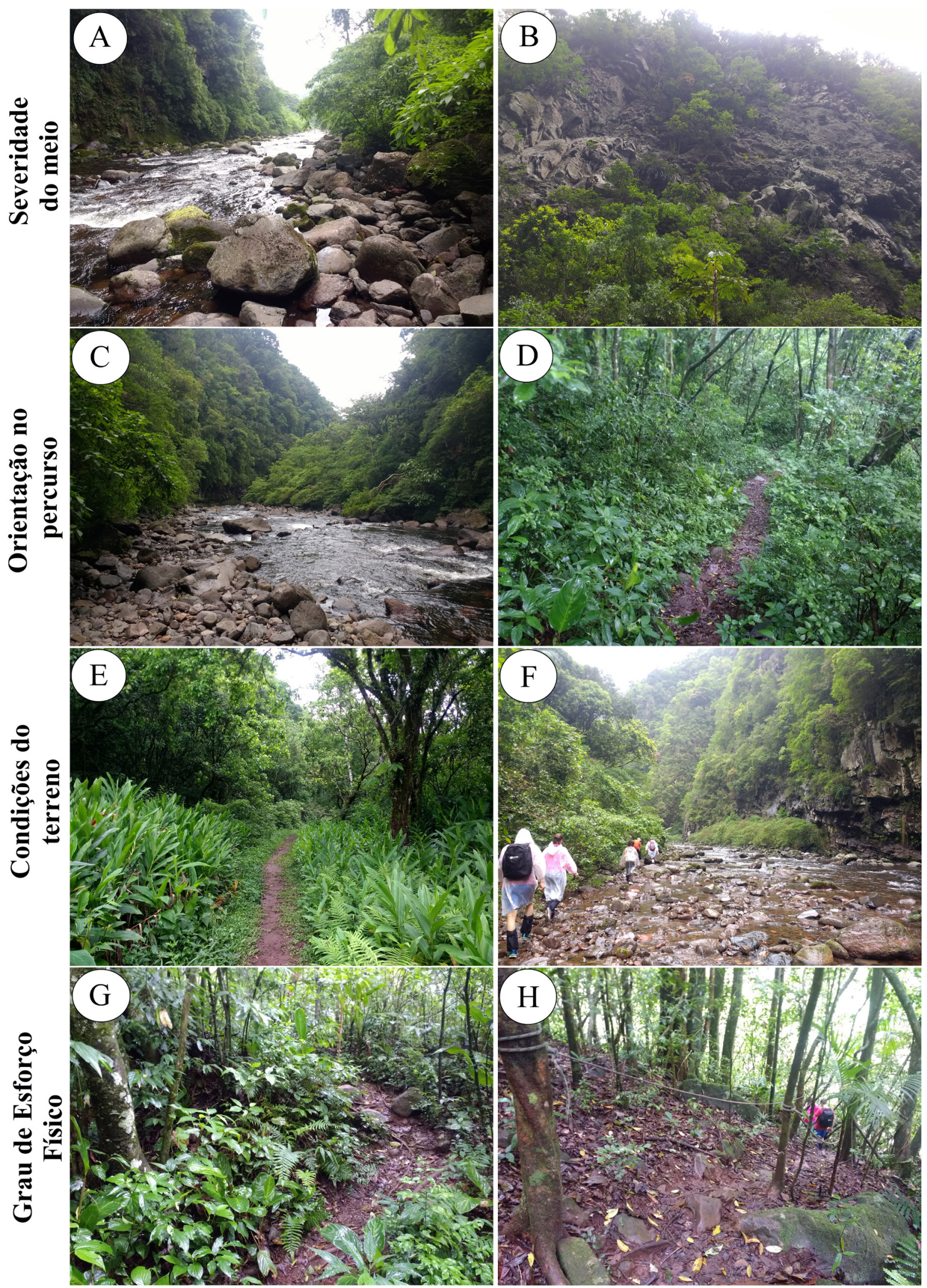

Figura 4 - Exemplificações de alguns trechos da Trilha do Rio do Boi. 
Nonnemacher et al. (2019) avaliaram de forma preliminar um potencial perigo em um trecho (mais especificamente o trecho 4 na Figura 2) da trilha do Rio do Boi, associado ao fluxo de detritos. Como a trilha inteira pode sofrer com esse fenômeno extremamente violento, os autores sugerem que a avaliação da trilha deva ocorrer de maneira integrada.
Igualmente, efetuou-se um resumo da contagem de trechos e da distância para o somatório final dos fatores de severidade do meio. Majoritariamente, os trechos foram classificados como "bastante severos" (22 trechos, correspondendo a $83 \%$ da distância total). A categoria "severo" contemplou 3 trechos $(5,4 \%$ do percurso), e "pouco severo", 2 trechos $(11,7 \%)$ (Figura 5).

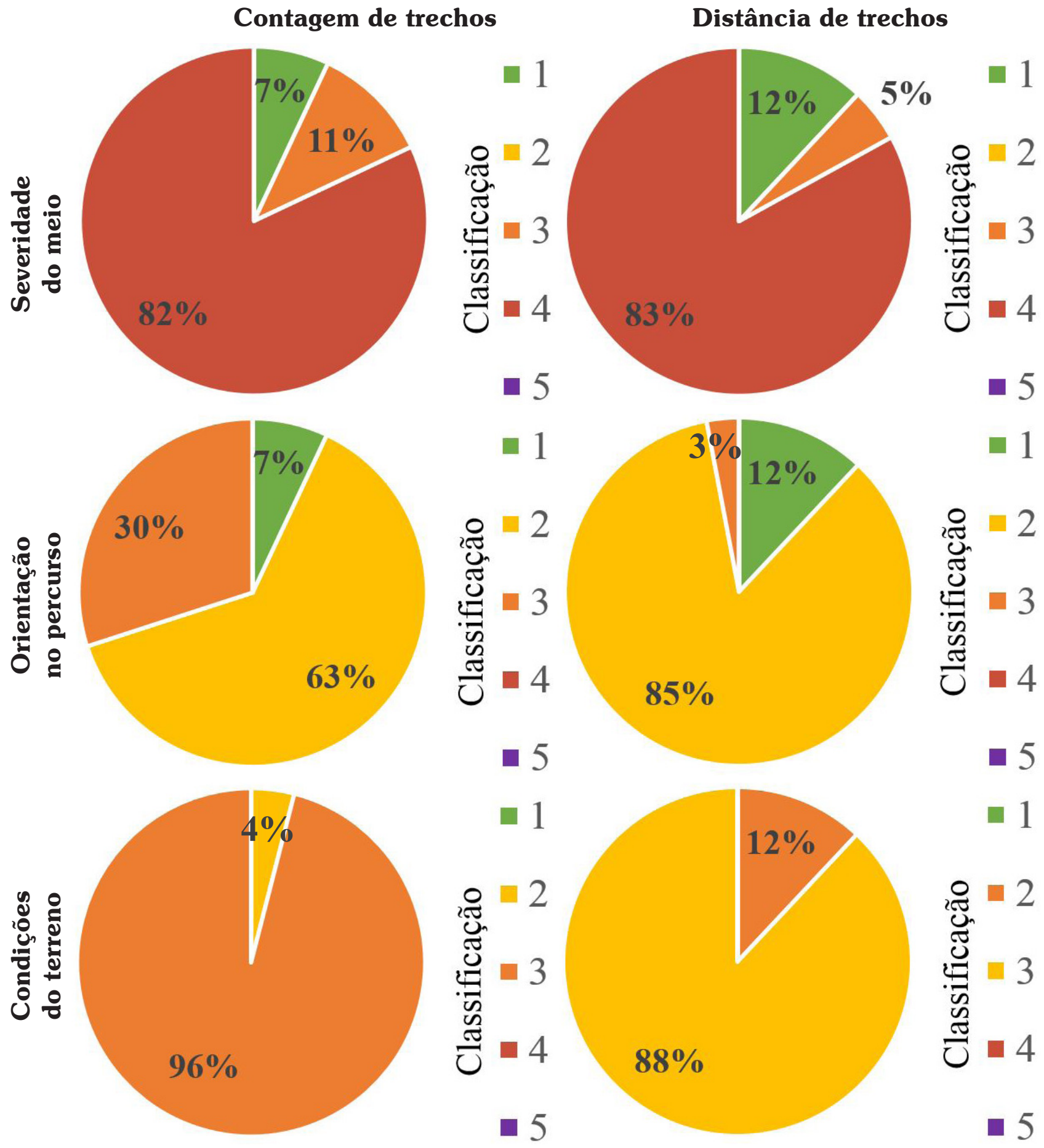

Figura 5 - Resumo dos resultados obtidos, em relação à contagem e ao somatório da distância dos trechos, segundo os critérios analisados. 
Quanto ao critério de orientação do percurso, a classe "caminho ou sinalização", que indica a continuidade, compreendeu 17 trechos (85\% em extensão do percurso). Exige a identificação de acidentes geográficos e de pontos cardeais, valor 3 , englobou os 8 trechos $(12 \%$ em extensão). O restante foi enquadrado como classe 1 (Caminhos e cruzamentos bem definidos), o qual corresponde aos primeiros dois trechos. Também se exemplificou um dos trechos de travessia pelo rio e o início da trilha de escape, respectivamente (Figuras 4C e 4D).

Para a penúltima classificação, condições do terreno, salvo o primeiro trecho da trilha (Figura
4E), todos os demais foram caracterizados pela classe 3 - percurso por trilhas escalonadas ou terrenos irregulares - representando, portanto, $88 \%$ do percurso (Figura $4 \mathrm{~F}$ ).

A partir das distâncias calculadas em uma ferramenta SIG, definiu-se as velocidades de $3 \mathrm{~km} / \mathrm{h}$ para os primeiros 4 trechos da trilha, e o valor de $2 \mathrm{~km} / \mathrm{h}$ para os demais. Desta forma, foram calculados os tempos de deslocamento horizontal para todos os trechos (Figura 6), assim como o acréscimo devido ao desnível, que foi considerado apenas para os trechos 3 e 5 , correspondentes aos extremos da trilha de escape. Para os demais segmentos, desconsiderou-se o desnível.

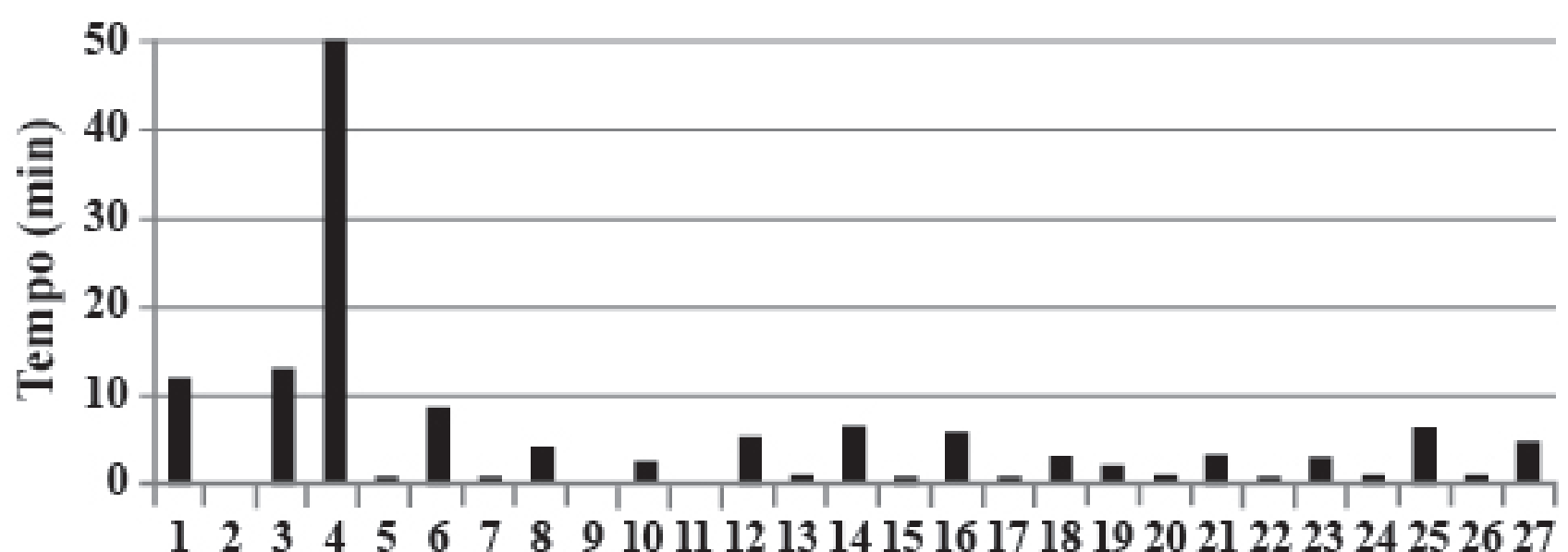

\section{Trecho}

Figura 6 - Tempo total de percurso dos 27 trechos definidos.

Como esperado, o trecho 4 (trilha de escape) apresentou o maior tempo de deslocamento horizontal (50min), principalmente devido à sua grande extensão. Desconsiderando-o, o tempo médio dos trechos foi 4,5min. Igualmente, estimouse o tempo adicional em virtude do desnível, encontrando $11 \mathrm{~min}$ para o trecho 3 e $8 \mathrm{~min}$ para o 5. Em razão de ser uma trilha de ida e volta pelo trajeto, considerou-se a menor velocidade estabelecida pela norma, isto é, $200 \mathrm{~m} / \mathrm{h}$ para subidas.

Estimou-se um índice de esforço físico (IE) de 4,4h para o percurso completo, indicando, assim, a categoria de esforço significativo. Caso fosse considerada apenas a ida, a classificação baixaria para moderado com 2,2h (Classe 2). Visualizamse o aclive (Figura 4G) e o declive (Figura 4H) existentes nos extremos da trilha de escape, e o tempo total de permanência por trecho.

Por fim, a NBR 15.505-2 ainda recomenda a disponibilização de um meio de comunicação dos resultados encontrados para as classificações aos guias, aconselhando a colocação da mesma no início do percurso (neste caso, junto ao Posto de Informação e Controle do Rio do Boi - ICMBio) ou em locais como os centros de informações turísticas, sugestão aos municípios de Cambará do Sul e de Praia Grande. Com base nos resultados obtidos, o presente trabalho propôs a seguinte placa para a Trilha do Rio do Boi (Figura 7). 


\section{Classificação de percurso de caminhada}

Percurso: Trilha do Rio do Boi

Atividade: Caminhada
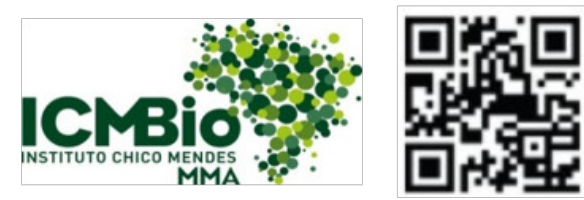

Trecho: Posto de Informação e Controle do Instituto Chico Mendes de Conservação da Biodiversidade (ICMBio) até Final da Trilha do Rio do Boi pela Trilha de Escape

Desníveis: Subidas: 100 m / Descidas: 223 m

Distância: $12 \mathrm{Km}$

Tempo médio total do percurso: 6 horas

Condições específicas: Sol parcialmente coberto com possibilidade de chuva

\begin{tabular}{|c|c|c|c|}
\hline $\begin{array}{l}\text { Grau de severi- } \\
\text { dade do meio }\end{array}$ & $\begin{array}{c}\text { Orientação do } \\
\text { percurso }\end{array}$ & $\begin{array}{l}\text { Grau técnico } \\
\text { do percurso }\end{array}$ & $\begin{array}{c}\text { Grau de esforço } \\
\text { físico }\end{array}$ \\
\hline 4 & $\begin{array}{l}3 \\
\text { Exige a identifica- } \\
\text { ção de acidentes } \\
\text { geográficos e de } \\
\text { pontos cardeais }\end{array}$ & $\begin{array}{c}3 \\
\text { Percurso por } \\
\text { trilhas escalona- } \\
\text { das ou terrenos } \\
\text { irregulares }\end{array}$ & $\begin{array}{c}3 \\
\text { esforço físico } \\
\text { significativo }\end{array}$ \\
\hline
\end{tabular}

*Os graus de classificação variam de 1 a 5 .

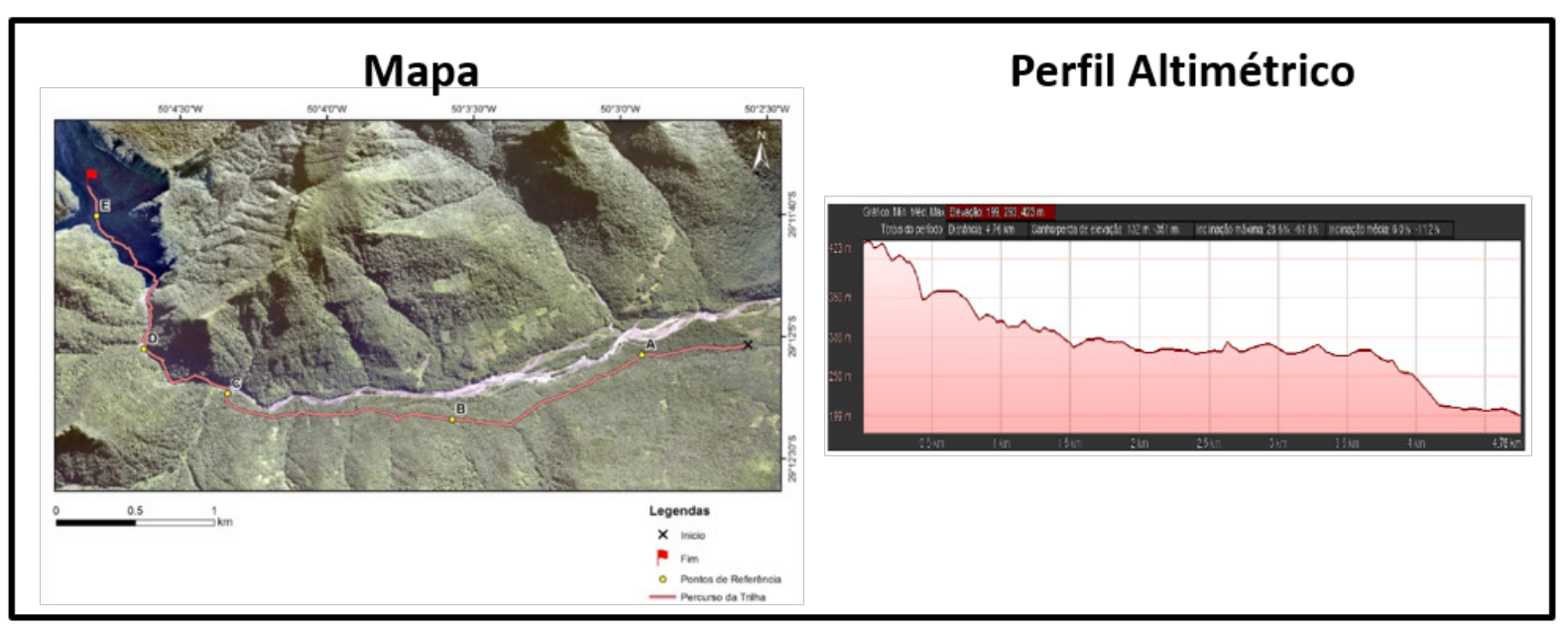

Percurso classificado conforme referência da ABNT NBR 15505-2

Figura 7 - Sugestão da placa de comunicação de classificação de percurso para a trilha do Rio do Boi. 


\section{Conclusões}

Apreciado como atrativo turístico, o PNAS vem obtendo popularidade, devido à sua maior divulgação e especialmente pela realização de trilhas dentro dos cânions. Tendo em vista a segurança dos turistas, é pertinente que sejam classificados os percursos, como a trilha do Rio do Boi. Assim, após a realização da caminhada, a trilha foi subdividida em 27 trechos, os quais foram analisados para quatro critérios, conforme a NBR 15.505-2:2019. As classificações obtidas são: Classe 4 (bastante severo); Classe 3 (exige a identificação de acidentes geográficos e de pontos cardeais); Classe 3 (percurso por trilhas escalonadas ou terrenos irregulares); e Classe 3 (esforço físico significativo). Observou-se que mais de $80 \%$ do percurso, no que concerne à orientação, compreende a Classe 2.

Além de orientar turistas, esse estudo visa embasar a tomada de decisão associada, especialmente, à prevenção de desastres. Dessa forma, como primeiras medidas, recomenda-se: instalação da placa de comunicação no local $e$ sua ampla divulgação aos órgãos pertinentes, adoção de placas sinalizadoras ao longo da trilha, desenvolvimento de programas de educação ambiental e conscientização de turistas $e$ aprofundamento de estudos de fenômenos naturais locais.

Deve-se levar em consideração que o presente trabalho foi uma classificação preliminar, sendo necessário realizar ainda seu aprimoramento. As trilhas possuem funções que vão além de deslocamento das pessoas e materiais, ou de educação ambiental, mas também pelo apoio para recuperação das áreas degradadas. Portanto, é muito importante desenvolver mais estudos de implantação e avaliação de trilhas. Com base na NBR 15.505-2:2019, sugere-se que o percurso seja ainda classificado por outras organizações (operadoras de turismo, entidades regulatórias, órgãos de fomento, entre outras).

Evidencia-se, assim, a relevância da contribuição da comunidade científica da hidrologia no gerenciamento de desastres em trilhas. A aplicação da hidrologia pode ser fundamental no caso da Trilha do Rio do Boi, já que os desastres naturais predominantes na mesma são de caráter hidrológico, isto é, inundação brusca e movimento de massas.
Por fim, a cognição de perigo é o primeiro passo na redução de danos e perdas causados por desastres. As comunidades de turismo têm cognição de risco/perigo e são mais sensíveis aos mesmos, buscando se adaptar ao risco de desastres, quando comparado a uma comunidade não-turística. Por conseguinte, o estabelecimento de trilhas com classificação do grau de perigo melhora não somente a segurança de turistas, mas também a estruturação da comunidade local.

\section{Agradecimentos}

Agradecemos ao GPDEN; à Guia Gezaela Magnus, pelo suporte na trilha; ao Gilvan Pereira, pelo auxílio na compreensão da norma; $e$ ao engenheiro ambiental Mauricio Paixão (GPDENUFRGS), pelas contribuições na idealização do estudo. $\mathrm{O}$ presente trabalho foi parcialmente financiado pelas agências brasileiras $\mathrm{CNPq} e$ CAPES-ANA (Programa Pró-Recursos Hídricos, $\left.\mathrm{n}^{\circ} 16 / 2017\right)$.

\section{Referências}

ABNT. NBR 15505-2: Turismo de aventura Caminhada - Parte 2: Classificação de percursos. Rio de Janeiro, ABNT, 2019. 14p.

Aguiar PW, Padua SM, Gomes MAO \& Uezu A. Subsídios para o planejamento de trilha no Parque Estadual da Serra Furada (SC). Revista Brasileira de Ecoturismo, 3(3): 498-527, 2010.

Andrade WJ \& Rocha RF. 2008. Manejo de trilhas: um manual para gestores. São Paulo: Instituto Florestal de São Paulo, Série Registros, n.35. 74p.

Brasil. 2008. Ecoturismo: orientações básicas. Brasilia: Ministério do Turismo, 60p.

Blengini IAD, Lima LB, Silva ISM \& Rodrigues C. Trilha interpretativa como proposta de Educação Ambiental: um estudo na RPPN do Caju (SE). Revista Brasileira de Ecoturismo, 12(1): 142-161, 2019.

Canto-Silva CR \& Silva JS. Panorama da visitação e da condução de visitantes em Parques brasileiros. Revista Brasileira de Pesquisa em Turismo, 11(2): 347-364, 2017.

Costa BC. Análise de trilha e sugestões de boas práticas. Revista Eletrônica em Gestão, Educação e Tecnologia Ambiental, 7(7): 1461-1478, 2012.

Donohoe HM \& Needham RD. Ecotourism: The Evolving Contemporary Definition. Journal of Ecotourism, 5(3), 192-210, 2006. 
Espiner S, Orchiston C \& Higham J. Resilience and sustainability: a complementary relationship? Towards a practical conceptual model for the sustainabilityresilience nexus in tourism. Journal of Sustainable Tourism, 25(10): 1385-1400, 2017.

Ferrarese MD, Corrêa LR, Rocha GL \& Ribeiro RC. Trilha interpretativa como instrumento de comunicação ambiental: uma experiência no Parque Natural Municipal dos Morros, Santa Maria (RS). Revista Brasileira de Ecoturismo, 12(2): 295-311, 2019.

Ferreira VJC. Avaliação das potencialidades e limitações da trilha da Pedra Selada e dos percursos para a Pedra Boca do Sapo no Parque Estadual da Pedra Selada (RJ). Revista Brasileira de Ecoturismo, 8(5): 556-578, 2015.

Garcia FO, Neiman Z \& Prado BHS. Planejamento de uma Trilha Interpretativa na Estação Ecológica de Angatuba (SP). Revista Brasileira de Ecoturismo, 4(3): 323-344, 2011.

Godoy MM, Binotto RB \& Wildner W. 2012. Geoparque Caminhos dos Cânions do Sul (RS/SC): proposta, p. 459-492. In: Schobbenhaus C \& Silva CR (orgs.). Geoparques do Brasil: propostas Volume 1, Rio de Janeiro: CPRM. 745p.

Hardiman N \& Burgin S. Adventure recreation in Australia: a case study that investigated the profile of recreational canyoners, their impact attitudes, and response to potential management options. Journal of Ecotourism, 9(1): 36-44, 2010.
Leite ML \& Virgens Filho JS. Avaliação da velocidade média e direção predominante do vento em Ponta Grossa - PR. Revista Brasileira de Agrometeorologia, 14(2): 157-167, 2006.

Magri TCS, Carvalho RCR, Magri RAF \& Andrade COP. Mapeamento, classificação e certificação de rotas de trekking em uma área do Parque Nacional da Serra da Canastra (MG). Revista Brasileira de Ecoturismo, 11(4): 645-672, 2018.

Melo SMC \& Aguiar EPS. Turismo de aventura em Taquaruçu - TO: Atividades e riscos. Turismo - Visão e Ação, 18(2): 280-299, 2016.

Neves CRF \& Costa VC. Avaliação Preliminar de Risco (APR) em atividades ecoturísticas na trilha do Pico da Tijuca, Parque Nacional da Tijuca (RJ). Revista Brasileira de Ecoturismo, 12(5): 685-701, 2019.

Nonnemacher LC, Franck AG \& Kobiyama M. Avaliação preliminar da segurança de turistas na trilha do rio do Boi no Parque Nacional Aparados da Serra. In: Anais do XXIII Simpósio Brasileiro de Recursos Hídricos. 2019. 10p.

Silva GGL, Lima TC \& Panchaud L. Mapeamento e Classificação do Grau de Dificuldade da Trilha do Rancho Caído, Parque Nacional do Itatiaia (RJ). Revista Brasileira de Ecoturismo, 9(2): 250-272, 2016.

Biodiversidade Brasileira - BioBrasil.

Edição Temática: Análise de Componentes do Sistema Climático e a Biodiversidade no Brasil

$$
\text { n. 4, } 2021
$$

http://www.icmbio.gov.br/revistaeletronica/index.php/BioBR

Biodiversidade Brasileira é uma publicação eletrônica científica do Instituto Chico Mendes de

Conservação da Biodiversidade (ICMBio) que tem como objetivo fomentar a discussão e a disseminação de experiências em conservação e manejo, com foco em unidades de conservação $e$ espécies ameaçadas.

ISSN: 2236-2886 